\title{
Immediate and early postoperative pain relief after kyphoplasty without significant restoration of vertebral body height in acute osteoporotic vertebral fractures
}

\author{
Carlos Feltes, M.D., Kostas N. Fountas, M.D., Ph.D., Theofilos Machinis, M.D., \\ LeOnidas G. NikolakaKos, M.D., Vassilios Dimopoulos, M.D., \\ Rostislav Davydov, M.D., MOZafFar KassaM, M.D., \\ Kim W. Johnston, M.D., AND Joe SAM Robinson, M.D.
}

Department of Neurosurgery, The Medical Center of Central Georgia, Mercer University School of Medicine, Macon, Georgia

\begin{abstract}
Object. Painful osteoporotic vertebral compression fractures (VCFs) are a significant cause of disability in the elderly population. Kyphoplasty, a recently developed minimally invasive procedure, has been advocated for the successful management of these fractures in terms of immediate pain relief, and also for restoration of the premorbid level of daily activities. In this retrospective study the authors report on their experience with the early management of VCFs with kyphoplasty.

Methods. A retrospective analysis was conducted in 13 patients (seven women and six men) whose ages ranged from 48 to 87 years (mean age $71.5 \pm 11$ years [mean \pm standard deviation]). The interval between onset of symptoms and surgical intervention ranged from 4 to 9 weeks. Twenty levels (12 thoracic, eight lumbar) were treated in this cohort. Immediate and early postoperative (1-month follow-up visit) visual analog scale (VAS) pain scores, activity levels, and restoration of vertebral body (VB) height were assessed.

The mean preoperative VAS score was $8 \pm 1$, whereas the immediate and early postoperative scores were $1 \pm 1$. These findings reflected a resolution of 90 to $100 \%$ of preoperative pain. All patients resumed routine activities within hours of the procedure, although improvement in VB height was not accomplished in this cohort. No major complications were encountered in this clinical series.

Conclusions. Kyphoplasty is a safe and effective method for the treatment of osteoporotic VCFs. Failure to restore VB height does not seem to interfere with the excellent pain management and good functional outcome provided by this procedure.
\end{abstract}

\section{KEY WORDS • osteoporosis • vertebral compression fracture • pain • kyphoplasty • polymethyl methacrylate}

Osteoporosis is the most common metabolic disorder of the bones, affecting approximately 28 million people in the US. ${ }^{16}$ It is estimated that $35 \%$ of all women older than 65 years of age suffer from this disorder, ${ }^{5}$ which predominantly affects postmenopausal women. Because age is the most important risk factor for osteoporosis, the number of affected individuals is anticipated to increase substantially in the coming years, as a result of the increase in life expectancy in the population of the industrialized countries. $^{7,34}$ In the US alone, approximately 1.5 million fractures occur annually as a result of primary or secondary osteoporosis, and almost half of those $(700,000)$ involve the spine. ${ }^{716,25,35}$

Osteoporotic VCFs are a significant cause of morbidity and mortality in postmenopausal women and elderly men.

Abbreviations used in this paper: PMMA = polymethyl methacrylate; VAS = visual analog scale; $\mathrm{VB}=$ vertebral body; $\mathrm{VCF}=$ vertebral compression fracture.
Fracture-related acute or chronic pain as well as gradual destruction of the VB with subsequent development of spinal kyphosis and abdominal protuberance interferes with the patient's daily activities and severely impairs their quality of life. Depression, poor nutritional status, decreased appetite, and impaired pulmonary function have been reported in patients who sustain VCFs. $7,14,23,24$ The impact on the patient's life increases with the number of vertebrae involved. The presence of one osteoporotic $\mathrm{VCF}$ leads to a fivefold increase in the risk of sustaining a second vertebral fracture, ${ }^{17}$ possibly due to altered biomechanical relationships in the spine as well as disease progression. Kado, et al., ${ }^{20}$ reported a $23 \%$ increase in the mortality risk in women with one VCF and a $34 \%$ increase when multiple VCFs are present.

In the last few years, balloon kyphoplasty, a minimally invasive procedure, has been developed for the treatment of painful VCFs, with quite promising results. This technique involves the percutaneous insertion and inflation of 
a bone tamp in the VB and subsequent low-force injection of a high-viscosity substance (PMMA), aiming to achieve pain relief and restoration of vertebral height. Nevertheless, the importance of the timing of the intervention and of the restoration of VB height has not been well established. In this communication, we present our experience with early management of this entity by using balloon kyphoplasty in 13 patients with osteoporotic VCFs.

\section{CLINICAL MATERIAL AND METHODS}

This is a retrospective clinical study of 13 patients (seven women and six men) whose ages ranged from 48 to 87 years; the mean age was 71.5 years \pm 11 years. The time interval between onset of symptoms and surgical treatment ranged from 4 to 9 weeks. All procedures were performed after induction of general anesthesia, with intraoperative somatosensory evoked potentials, motor evoked potentials, and electromyographic monitoring used for every case. In this cohort we attempted to restore a total of 20 levels (12 thoracic, eight lumbar) with a percutaneous surgical method in which a unilateral extrapedicular approach was used on the thoracic levels and a bilateral transpedicular approach on the lumbar levels. All the procedures were performed with the aid of fluoroscopic guidance. We routinely used PMMA as a filling agent in these procedures. In no case was more than $3 \mathrm{ml}$ of PMMA used, to prevent delayed adjacent VCFs. ${ }^{31}$

Immediate and 1-month postoperative VAS pain scores were obtained; also, activity levels and restoration of VB height were assessed independently for each case.

\section{RESULTS}

The pre- and postoperative VAS scores were calculated and were found to be $8 \pm 1$ and $1 \pm 1$, respectively. These immediate and early postoperative findings demonstrated resolution of 90 to $100 \%$ of the preoperative pain (Fig. 1). All patients resumed their routine activities within hours of the procedure and were discharged within 24 hours. No significant improvement in VB height was accomplished in this cohort (Figs. 2 and 3). No major complications were encountered.

\section{DISCUSSION}

Osteoporotic VCFs constitute an increasing source of morbidity and disability among the elderly popula-

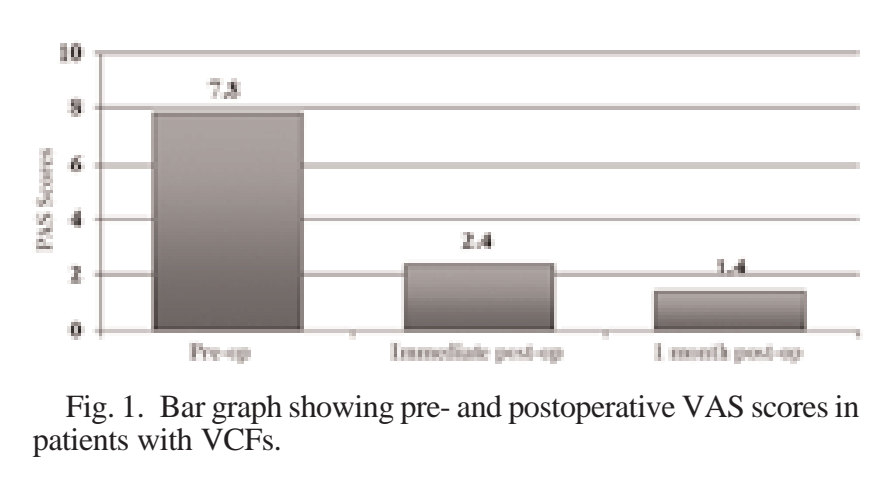

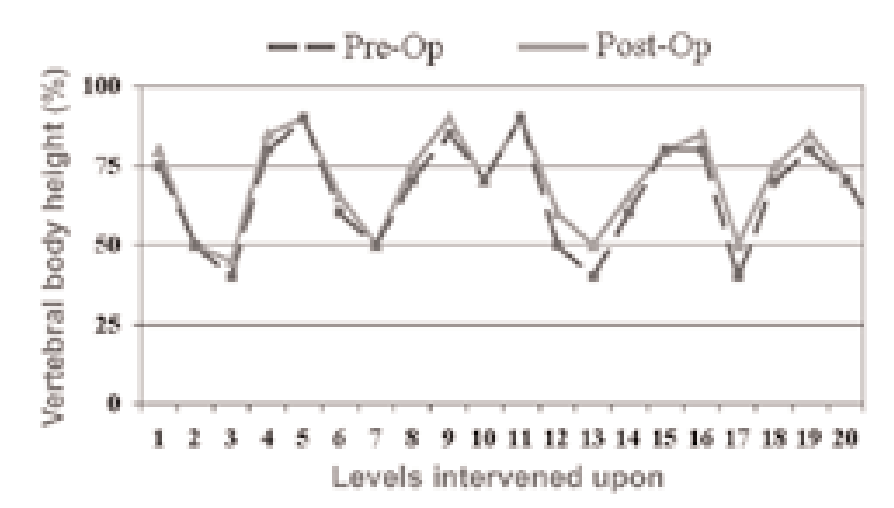

Fig. 2. Graph showing pre- and postoperative VB height in patients undergoing kyphoplasty.

tion. ${ }^{4,30,32}$ The negative impact of these entities on the ability to perform daily activities is of paramount importance; approximately $50 \%$ of patients with more than one VCF are in need of daily self-care assistance. ${ }^{28}$ Treatment of VCFs has traditionally been conservative, consisting of bed rest, analgesic drugs, and back brace ${ }^{29}$ in severe cases, along with other pain-relieving methods such as massage and heat therapy. ${ }^{21,24}$ Immobilization, however, is a well-known predisposing factor for further bone loss, resulting in an increased tendency to sustain additional osteoporotic fractures, and reinforcing an already existent vicious cycle. Additionally, prolonged therapy with pain medication may lead to confusion and gastrointestinal and addiction problems.

In an effort to prevent further fractures and to achieve early pain relief and mobilization of these patients, vertebroplasty, a minimally invasive technique, was developed. Vertebroplasty was first described by Galibert, et al., in $1987^{11}$ for the treatment of VB tumors, and its use has since been expanded to include osteoporotic VCFs. This procedure entails the high-force injection of low-viscosity PMMA in the VB. Vertebroplasty achieves excellent pain relief; 60 to $100 \%$ of treated patients experience a significant improvement within a few days. ${ }^{1,5,6,10,28}$ Nevertheless, the injection of PMMA under high pressure carries a substantial risk of extravertebral cement leakage; Cortet, et al., ${ }^{6}$ reported that leakage was observed in $65 \%$ of their patients. Depending on the extent and the exact location of the leakage, a variety of complications may develop. Perivertebral venous migration of the cement might lead to pulmonary embolism ${ }^{3}$ and death, and foraminal or epidural cement extravasation may cause nerve root or spinal cord compression with subsequent neurological symptoms that require surgical intervention. ${ }^{8,21,26}$ Furthermore, vertebroplasty fails to achieve restoration of VB height and spinal realignment. ${ }^{7,9,18}$ The kyphotic deformity is "frozen," and this is believed to correlate with an increased risk of adjacent VCFs and impaired functional outcome.

The recently developed percutaneous balloon kyphoplasty procedure is aimed at addressing the shortcomings of vertebroplasty, and has been gaining popularity, especially among physicians in the surgical subspecialties. Kyphoplasty results in immediate relief of the fracture pain, comparable to vertebroplasty., ${ }^{2,13,18,22}$ Lieberman, et al., ${ }^{24}$ 


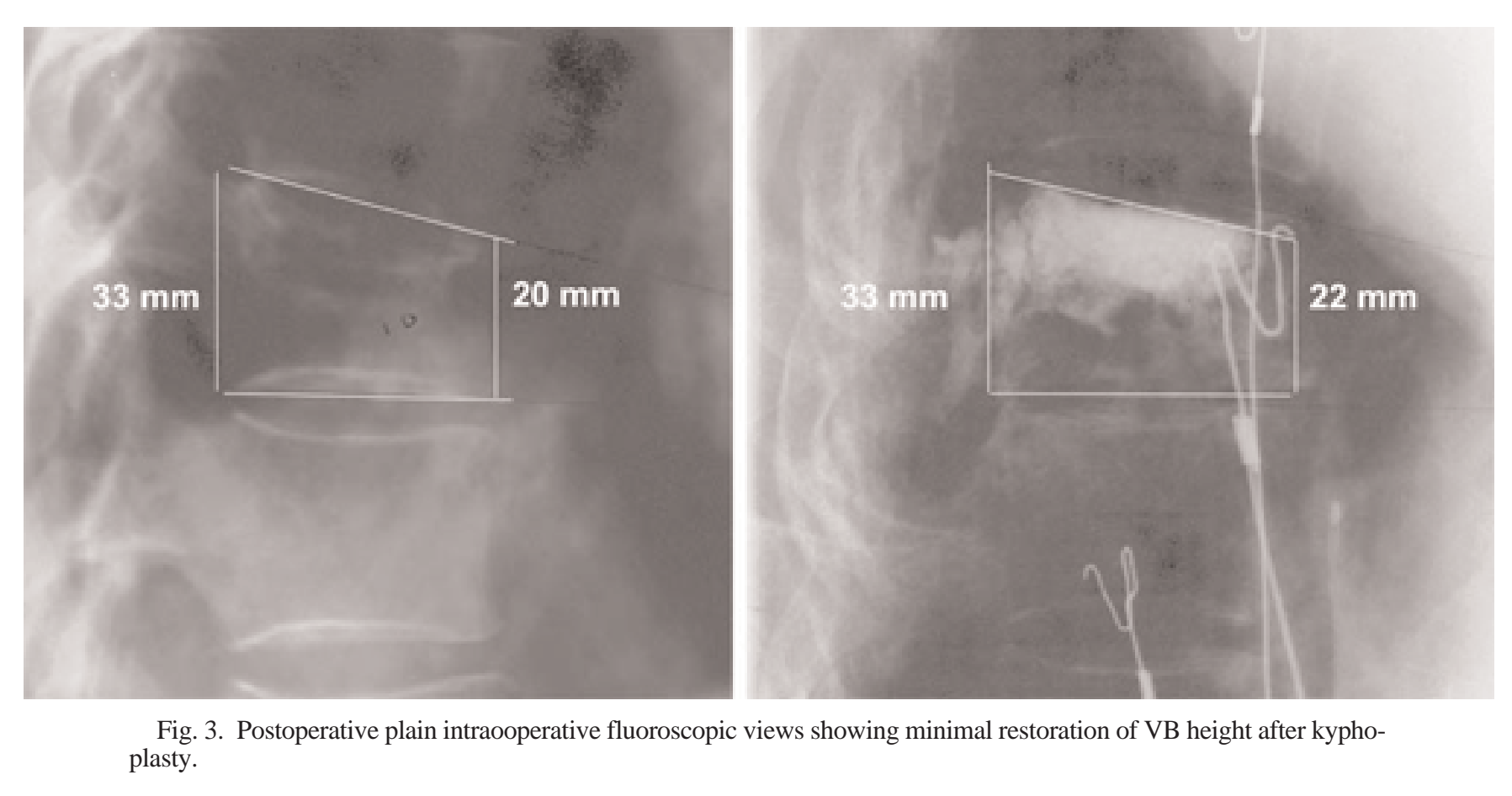

found that all of their patients treated with kyphoplasty noted a marked reduction in the intensity of pain after the procedure. Garfin, et al. ${ }^{12}$ reported similar results in a retrospective study, with $90 \%$ of patients in their cohort experiencing significant pain relief within 2 weeks. Our results confirm those of previously published reports. The exact mechanism of pain relief by vertebral augmentation procedures remains unknown; postulated mechanisms include a chemical or thermal effect of PMMA resulting in the destruction of nerve endings transmitting pain signals, as well as a mechanical stabilization of microfractures. ${ }^{6,15,19}$

Extravasation of cement appears to occur much less frequently with kyphoplasty in comparison with vertebroplasty. The low-force injection of a higher-viscosity material along with the packing and hardening of the cancellous bones accomplished by the balloon inflation seem to confine PMMA effectively inside the vertebra. Coumans, et al., ${ }^{7}$ reported only a $2.7 \%$ risk of material leakage per treated level in a cohort including patients with osteoporosis as well as those with multiple myeloma, who are generally considered more prone to intraoperative complications such as cement leakage. Lieberman, et al., ${ }^{24}$ and Ledlie and Renfro, ${ }^{22}$ reported cement extravasation rates of 8.6 and $9 \%$, respectively. No cement leakage was noted in our cohort, which further supports the safety of this procedure.

In several series, kyphoplasty has been indicated to achieve partial VB height restoration, which is considered important for correction of the kyphotic deformity., $213,22,24$ Lieberman, et al., ${ }^{24}$ reported a $47 \%$ increase in midline VB height in $70 \%$ of the treated levels, although they stated that longer follow-up duration is required before definite conclusions can be made. Similarly, Berlemann, et al.,2 noted a $47.7 \%$ correction of local osseous kyphosis. They also observed a relationship between the age of the frac- ture, the amount of preoperative kyphosis, and the location of the vertebra in terms of the potential for height restoration; recent fractures ( $<6$ weeks old) that are caudally located with a severe kyphotic deformity are more likely to show significant restoration of VB height after kyphoplasty. ${ }^{2}$ Improvement of local sagittal alignment in the region of the fracture has also been reported in the literature. $27,33,34$

In our series, no statistically significant increase in VB height was noted, despite early intervention. Nevertheless, all patients resumed normal daily activities within hours after the procedure, and their functional level has remained unchanged throughout the entire follow-up period. This indicates that early management of osteoporotic VCFs with kyphoplasty may lead to a desirable functional outcome and marked improvement in the quality of life, even without restoration of the VB height.

\section{CONCLUSIONS}

The treatment of osteoporotic VCFs with kyphoplasty appears to provide significant pain reduction and restores patients to their premorbid level of daily activities. Complications associated with this procedure seem to be minimal. Nevertheless, large, long-term, clinical randomized prospective studies need to be conducted for an adequate assessment of the life-long results as well as the eventual shortcomings of kyphoplasty. For instance, the exact behavior of PMMA several decades after its placement remains to be elucidated.

\section{References}

1. Barr JD, Barr MS, Lemley TJ, et al: Percutaneous vertebroplasty for pain relief and spinal stabilization. Spine 25:923-928, 2000 
2. Berlemann U, Franz T, Orler R, et al: Kyphoplasty for treatment of osteoporotic vertebral fractures: a prospective non-randomized study. Eur Spine J 13:496-501, 2004

3. Choe DH, Marom EM, Ahrar K, et al: Pulmonary embolism of polymethyl methacrylate during percutaneous vertebroplasty and kyphoplasty. AJR 183:1097-1102, 2004

4. Cook DJ, Guyatt GH, Adachi JD, et al: Quality of life issues in women with vertebral fractures due to osteoporosis. Arthritis Rheum 36:750-756, 1993

5. Cortet B, Cotten A, Boutry N, et al: Percutaneous vertebroplasty in patients with osteolytic metastases or multiple myelomas. Rev Rhum Engl Ed 64:177-183, 1997

6. Cortet B, Cotten A, Boutry N, et al: Percutaneous vertebroplasty in the treatment of osteoporotic vertebral compression fractures: an open prospective study. J Rheumatol 26:2222-2228, 1999

7. Coumans JV, Reinhardt MK, Lieberman IH: Kyphoplasty for vertebral compression fractures: 1-year clinical outcomes from a prospective study. J Neurosurg Spine 99:44-50, 2003

8. Diamond TH, Champion B, Clark WA: Management of acute osteoporotic vertebral fractures: a nonrandomized trial comparing percutaneous vertebroplasty with conservative therapy. Am J Med 114:257-265, 2003

9. Dudeney S, Lieberman IH, Reinhardt MK, et al: Kyphoplasty in the treatment of osteolytic vertebral compression fractures as a result of multiple myeloma. J Clin Oncol 20:2382-2387, 2002

10. Einhorn TA: Vertebroplasty: an opportunity to do something really good for patients. Spine 25:1051-1052, 2000

11. Galibert $P$, Deramond $H$, Rosat $P$, et al: Note preliminaire sur le traitement des angiomes vertebraux par vertebroplastie percutanee. Neurochirurgie 33:166-168, 1987

12. Garfin S, Lin G, Lieberman I, et al: Retrospective analysis of the outcomes of balloon kyphoplasty to treat vertebral body compression fracture (VCF) refractory to medical management. Eur Spine J 10 (Suppl 1):S7, 2001

13. Garfin SR, Yuan HA, Reiley MA: New technologies in spine: kyphoplasty and vertebroplasty for the treatment of painful osteoporotic compression fractures. Spine 26:1511-1515, 2001

14. Gold DT: The clinical impact of vertebral fractures: quality of life in women with osteoporosis. Bone 18 (Suppl):1855-1895, 1996

15. Halpin RJ, Bendok BR, Liu JC: Minimally invasive treatments for spinal metastases: vertebroplasty, kyphoplasty and radiofrequency ablation. J Support Oncol 2:339-355, 2004

16. Harrop JS, Prpa B, Reinhardt MK, et al: Primary and secondary osteoporosis' incidence of subsequent vertebral compression fractures after kyphoplasty. Spine 29:2120-2125, 2004

17. Heaney RP: The natural history of vertebral osteoporosis. Is low bone mass an epiphenomenon? Bone 13:S2-S26, 1992

18. Heini PF, Orler R: Kyphoplasty for treatment of osteoporotic vertebral fractures. Eur Spine J 13:184-192, 2004

19. Jefferiss CD, Lee AJC, Ling RSM: Thermal aspects of self curing polymethylmethacrylate. J Bone Joint Surg Br 57: 511-518, 1975
20. Kado DM, Browner WS, Palermo L, et al: Vertebral fractures and mortality in older women: a prospective study. Study of the Osteoporotic Fractures Research Group. Arch Intern Med 159:1215-1220, 1999

21. Lane JM, Johnson CE, Khan SN, et al: Minimally invasive options for the treatment of osteoporotic vertebral compression fractures. Orthop Clin North Am 33:431-438, viii, 2002

22. Ledlie JT, Renfro M: Balloon kyphoplasty: one-year outcomes in vertebral body height restoration, chronic pain, and activity levels. J Neurosurg Spine 98:36-42, 2003

23. Leech JA, Dulberg C, Kellie S, et al: Relationship of lung function to severity of osteoporosis in women. Am Rev Respir Dis 141:68-71, 1990

24. Lieberman IH, Dudeney S, Reinhardt MK, et al: Initial outcome and efficacy of "kyphoplasty" in the treatment of painful osteoporotic vertebral compression fractures. Spine 26:1631-1638, 2001

25. Lin JT, Lane JM: Osteoporosis: a review. Clin Orthop 425: 126-134, 2004

26. Nussbaum DA, Gailloud P, Murphy K: A review of complications associated with vertebroplasty and kyphoplasty as reported to the Food and Drug Administration medical device related web site. J Vasc Interv Radiol 15:118-119, 2004

27. Phillips FM: Minimally Invasive Treatments of Osteoporotic Vertebral Compression Fractures. Spine 28 (Suppl 15): S45-S53, 2003

28. Phillips FM, Ho E, Campbell-Hupp M, et al: Early radiographic and clinical results of balloon kyphoplasty for the treatment of osteoporotic vertebral compression fractures. Spine 28: 2260-2267, 2003

29. Ray NF, Chan JK, Thamer M, et al: Medical expenditures for the treatment of osteoporotic fractures in the United States in 1995: report from the National Osteoporosis Foundation. J Bone Miner Res 12:24-35, 1997

30. Riggs BL, Melton LJ III: The worldwide problem of osteoporosis: insights afforded by epidemiology. Bone 17 (Suppl 5): 505S-511S, 1995

31. Scott J, Huskisson EC: Graphic representation of pain. Pain 2: 175-184, 1976

32. Silverman $\mathrm{S}$ : The clinical consequences of vertebral compression fracture. Bone 13 (Suppl):27-32, 1992

33. Theodorou DJ, Theodorou SJ, Duncan TD, et al: Percutaneous balloon kyphoplasty for the correction of spinal deformity in painful vertebral body compression fractures. Clin Imaging 26:1-5, 2002

34. Truumees E: Osteoporosis. Spine 26:930-932, 2001

35. Truumees E, Hilibrand A, Vaccaro AR: Percutaneous vertebral augmentation. Spine J 4:218-229, 2004

Manuscript received January 18, 2005.

Accepted in final form Feburary 23, 2005.

Address reprint requests to: Kostas N. Fountas, M.D., Ph.D., 840

Pine Street, Suite 880, Macon, Georgia 31201. email: knfountasmd @excite.com. 